\title{
Heavy Metal Concentrations in Dairy Products from Sheep Milk Collected in Two Regions of Southern Italy
}

By Aniello Anastasio ${ }^{a}$ Rosa Caggiano $^{b}$, Maria Macchiato $^{c}$, Catellani Paolo ${ }^{d}$, Maria Ragosta ${ }^{e}$, Salvatore Paino ${ }^{\prime}$, M.L. Cortesi ${ }^{a}$

\author{
aDipartimento di Scienze Zootecniche e Ispezione degli Alimenti, Universita 'Federico II, Napoli, Italy \\ 'IMAA, Istituto di Metodologie per l' Analisi Ambientale CNR, Tito Scalo (PZ), Italy \\ 'INFM, Dipartimento di Scienze Fisiche, Universita` Federico II, Napoli, Italy \\ dDipartimento di Sanità Pubblica, Patologia Comparata ed Igiene Veterinaria, Università di Padova, Italy \\ 'INFM, Dipartimento di Ingegneria e Fisica dell' Ambiente, Universita' della Basilicata, Via dell'Ateneo Lu- \\ cano, 85100 Potenza, Italy \\ fDipartimento di Scienze della Produzione Animale, Universita` della Basilicata, Potenza, Italy.
}

\section{Introduction}

Inorganic or aggregated forms of chemical substances (metalloids, heavy metals etc.) in feed and food represent a severe risk for their longterm toxicological effects. Heavy metals are widely dispersed in the environment. The toxicity induced by excessive levels of some of these elements, such as chromium (Cr), cadmium $(\mathrm{Cd})$, lead $(\mathrm{Pb})$ and mercury $(\mathrm{Hg})$, are well known (Llobet J.M. et al., 2003).

The toxic metal content of milk and dairy products is due to several factors - in particular - environmental conditions, the manufacturing process and the possible contamination during several steps of the manufacturing processes.

Southern Italy with more than 1.000 .000 sheep represents an important source of income for rural areas of this territory. The milk from sheep is almost entirely used to produce cheese. At present, no data are available concerning levels of heavy metal contamination in milk and dairy products from sheep in Calabria and Campania - two regions of southern Italy.

The aim of this work was to detect the concentrations of some heavy metals in milk collected

from ewes in several farms in Calabria and Campania and to evaluate to what extent these metals may be present in dairy products for human consumption. This study is a part of a work published elsewhere (Caggiano R. et al., 2005).

\section{Experimental data and methods}

The samples were collected in 8 farms located in Campania (5) and Calabria (3) (Figure 1). The sampling sites are located in places with different pollution impact (high volume of traffic, industrial plants, dumps, waste incinerators, metropolitan areas, small-medium towns, intensive agricultural activities).

\section{Sampling protocols}

Samples of milk, ricotta and caciotta cheese at different ripening times were analysed to detect chromium, cadmium, lead and mercury. All the samples were collected according to Italian Official Analytical Methods, 1986 and followed rigorous procedures (no metallic containers, mechanical milkers etc.) in order to minimize possible external contaminations. Each milk 
Table 1: Levels ( $\mu \mathrm{g} / \mathrm{g}$ d.w.) of chromium, cadmium, lead and mercury in ewe's milk, fresh, mature cheese and ricotta collected in 8 farms located in southern Italy.

\begin{tabular}{|c|c|c|c|}
\hline Elements & Min* & Max & $\mathrm{M} \pm \mathrm{SD}$ \\
\hline \multicolumn{4}{|c|}{ Milk } \\
\hline $\mathrm{Cr}$ & 0.06 & 0.40 & $0.14 \pm 0.113$ \\
\hline $\mathrm{Cd}$ & 0.05 & 0.10 & $0.07 \pm 0.019$ \\
\hline $\mathrm{Pb}$ & 0.11 & 0.28 & $0.18 \pm 0.069$ \\
\hline $\mathrm{Hg}$ & 0.0014 & 0.0029 & $0.002 \pm 0.005$ \\
\hline \multicolumn{4}{|c|}{ Ricotta } \\
\hline $\mathrm{Cr}$ & 0.03 & 0.68 & $0.32 \pm 0.226$ \\
\hline $\mathrm{Cd}$ & 0.06 & 0.24 & $0.13 \pm 0.212$ \\
\hline $\mathrm{Pb}$ & 0.12 & 0.70 & $0.391 \pm 0.212$ \\
\hline $\mathrm{Hg}$ & 0.0006 & 0.0028 & $0.0017 \pm 0.0008$ \\
\hline \multicolumn{4}{|c|}{ Fresh cheese } \\
\hline $\mathrm{Cr}$ & 0.40 & 0.53 & $0.46 \pm 0.042$ \\
\hline $\mathrm{Cd}$ & 0.05 & 0.35 & $0.19 \pm 0.114$ \\
\hline $\mathrm{Pb}$ & 0.13 & 1.15 & $0.47 \pm 0.365$ \\
\hline $\mathrm{Hg}$ & 0.0006 & 0.0017 & $0.008 \pm 0.0005$ \\
\hline \multicolumn{4}{|c|}{ Mature cheese } \\
\hline $\mathrm{Cr}$ & 0.34 & 0.67 & $0.47 \pm 0.102$ \\
\hline $\mathrm{Cd}$ & 0.06 & 0.15 & $0.11 \pm 0.041$ \\
\hline $\mathrm{Pb}$ & 0.21 & 1.07 & $0.58 \pm 0.271$ \\
\hline $\mathrm{Hg}$ & 0.0002 & 0.0056 & $0.0014 \pm 0.0001$ \\
\hline
\end{tabular}

$*_{\min }=$ minimum, $\max =$ maximum, $\mathrm{M}=$ mean value $\mathrm{SD}=$ standard deviation

sample was composed of seven samples taken during the morning milking. An aliquot was stored at $-18^{\circ} \mathrm{C}$ until analysis. The remaining part of the milk was processed in order to produce ricotta and caciotta a typical kind of cheeses with different ripening periods.

Ricotta is a fresh, "rindless" (i.e. without external rind) cheese with a compact, smooth, white or white-ivory paste. To produce this cheese, the residual whey from cheese making is filtered once and then heated. The whey is heated a second time (ricotta means "re-cooked") until sero-proteins coagulate into particles and rise to the top for collection. The clotting on the surface of the whey is gently skimmed with a "spannarola"(a wood or metallic ladle used to 


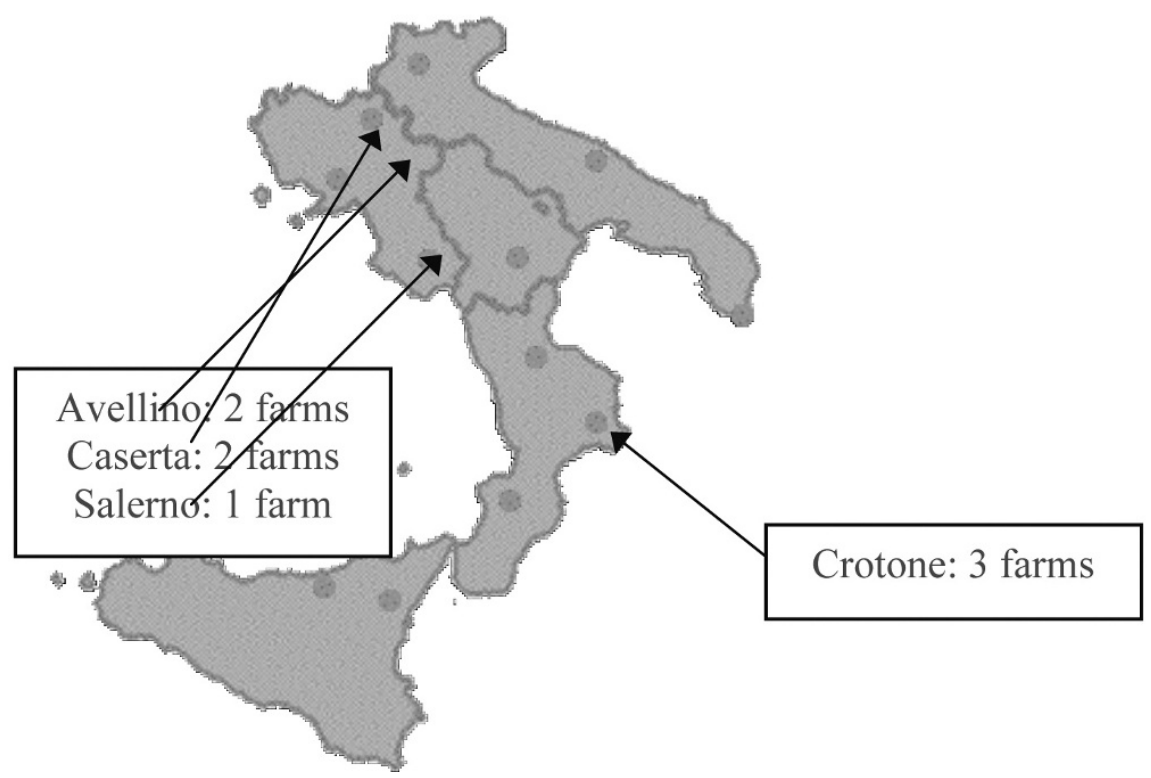

Figure 1: Study area. Campania ( $\mathrm{n}=5$ farms) and Calabria $(\mathrm{n}=3$ farms) regions.

collect cream on the surface) and deposited in special baskets made of plastic or rush.

Caciotta is a seed-shaped, cheese with brief to long ripening periods. To make this cheese, raw sheep milk is filtered through cloths, introduced into a vat and heated to a coagulation point at $36-38^{\circ} \mathrm{C}$. Kid's rennet paste is mixed in to ensure coagulation within one hour. At this point, the well-hardened curd is broken up using a wooden stick from the fig tree and then cooked to $40-44{ }^{\circ} \mathrm{C}$. The granules of curd settle to the bottom of the vat and are then picked up as a mass. This is divided into several rush basket moulds. The cheese is then pressed and squeezed energetically. The moulds are then dipped into warm whey at $50^{\circ} \mathrm{C}$ for a few minutes, followed by a dry salting. The ripening period range from 8 to 60 days.

\section{Trace elements analysis}

The analysis of chromium, cadmium, lead and mercury was performed in a Varian AA200 atomic absorption spectrophotometer equipped with a graphite furnace (GFAAS).

A microwave system was used for acid digestion of all the samples. All the samples (milk and dairy products) were dried at $70{ }^{\circ} \mathrm{C}$ in a forced stove until dry weight. To a dry sample of $0,3 \mathrm{~g}$, finely crushed, were added $6.0 \mathrm{ml}$ of $\mathrm{HNO}_{3}(65 \%)$ and $1.0 \mathrm{ml}$ of $\mathrm{H}_{2} \mathrm{O}_{2}(30 \%)$. The solution was filtered, deionised water $(50 \mathrm{ml})$ was added and the sample was then stored in PET bottles.

The determination of $\mathrm{Hg}$ content in dry samples was carried out by means of an automatic Mercury analyser (AMA 254) that was able to measure 0 concentrations of mercury without chemical pre-treatment. 
The accuracy of instruments and analytical procedures were checked with certified reference materials (Non fat milk powder, National Bureau of Standards, Gaithersburg, USA).

\section{Results and Discussion}

The concentrations of metals in samples analysed are reported in Table 1. Chromium was the metal detected at highest levels in milk and lead was highest in fresh, mature cheese and in ricotta. The compounds detected at lowest concentrations were cadmium in milk, fresh and mature cheese $(0.05 \mu \mathrm{g} / \mathrm{g}, 0.05 \mu \mathrm{g} / \mathrm{g}$ and 0.06 $\mu \mathrm{g} / \mathrm{g})$ and chromium in ricotta $(0.03 \mu \mathrm{g} / \mathrm{g})$.

Lead and chromium levels detected in this study were higher than those reported in literature for milk and dairy sheep samples collected in other sites of Italy (Coni et al. 1996) and in similar bovine samples collected in the same area (Licata et al., 2004).

The results show different patterns of heavy metal contents in milk, ricotta and cheese samples. The chemical and physical properties of the manufacturing process may thus influence the metal concentrations. Except for lead, where the rise in mature cheese (mean value $0.58 \mu \mathrm{g} / \mathrm{g}$ ) was due probably to environmental pollution, the ripening process didn't affect the metal levels.

Chromium showed a remarkable increase from raw milk to cheese. The high levels may be ascribed to that this chromium is preferentially bound to milk components such as caseins and during the curdling step move mainly in curd. Chromium is used in the leather industry, in inks and in processing of steel, (de Souza et al., 2002). Near the sampling sites in the Campania region, where the highest levels of this metal were detected, there are some of those types of industries. EU regulations have not yet fixed limits for chromium in milk or in dairy products. However, the mean chromium value observed was lower than the limit established by the Italian National Residues Plan for ovine spleen tissue, which is considered as a bio accumulator of this metal. Our conclusion is that, since chromium concentrations increased in all cheese products examined it would be advisable to establish maximum limits for this compound not only in milk but also in other dairy products.

Lead values showed a notable increase from $0.18 \mu \mathrm{g} / \mathrm{g}$ in milk to $0.39 \mu \mathrm{g} / \mathrm{g}$ in ricotta. This rise could be a consequence of contamination during the cheese making process, since only metals initially present are bound to milk proteins. The further increase of lead levels in ripened cheese cannot be explained by water loss but was probably caused by environmental conditions at the ripening sites.

Lead concentrations, exceeding the maximum limit of $0.02-\mathrm{mg} / \mathrm{Kg}$ w.w. (EU Regulation 2001/466 (for bovine milk)) were found in some ricotta samples. Lead, due to its wide use in industrial processes, ranks as the metal of largest diffusion through the atmosphere (SEMA, 1998). One could speculate that this could in part explain the high concentrations found in sites relatively far from the urban areas and industrial plants.

Cadmium concentrations did not vary greatly between the different final products suggesting that this compound was more closely associated with the soluble fraction and probably equally distributed between caseins and components of low molecular mass. Overall cadmium concentrations were comparable to values reported in literature and were below the maximum limit of $500 \mu \mathrm{g} / \mathrm{Kg}$ w.w. (EU Regulation 2001/466 (for ovine liver)). There are no specific limits for cadmium in milk and dairy products. However, it is essential to remember that cadmium presents high toxicity.

The highest levels of mercury were detected in fresh cheese. The decrease of concentrations from milk to ricotta was imputable to manufac- 
turing process. The overall mercury levels were similar or lower to values reported in literature (Llobet M.J. et al., 2003).

As regards correlation between pollution degree at sampling sites and metal levels in milk and cheese samples the results do not point out significant differences. In milk, ricotta, fresh and mature cheese samples coming from sites more polluted (Caggiano R. et al., 2005), cadmium and chromium concentrations were lower (with the only exception of one samples of fresh cheese) than in milk from sites with low environmental contamination (Caggiano $R$. et al., 2005). The highest lead levels were detected in ricotta, fresh and mature cheese (six, ten and 1.5 fold the lowest value respectively) sampled in a farm located in an area with low pollution index. Only for mature cheese the mercury concentrations were higher in polluted than nonpolluted sites.

In Italy, human consumption of sheep milk is very limited and addressed to milk products. In our study the levels of some metals were higher than those reported in literature. However, the results indicate that sheep milk and milk products from the two regions of Italy investigated in this study are safe for consumers. There are not precise data on sheep cheese consumption. Even if we estimate an average daily consumption very high and taking into account the mean level of lead, the metal detected at highest concentrations in cheese, the contribution to the dietary intake is lower than Provisional Tolerable Daily Intake reported by the Joint FAO/WHO expert on food additives (FAO/WHO, 1993).

\section{References}

Caggiano R, Sabia S, D’Emilio M, Macchiato $M$, Anastasio A, Ragosta M, Paino $S$ :

Metal levels in fodder, milk, dairy products, and tissues sampled in ovine farms of southern Italy. Environmental Research, 2005, 99(1): 48-57.

CE Regulation 2001/466: Off. J. Eur. Comm., 2001, L 039, 21

Coni E, Bocca A. Coppolelli P, Caroli S, Cavallucci C, Trabalza Marinucci M:

Minor and trace element content in sheep and goat milk and dairy products. Food Chem. 1996, 57, 253-260.

Coni E, Bocca A, Caroli S: Minor and trace element content of two typical Italian sheep dairy products. J. Dairy Res. 1999, 66, 589-598.

de Souza Lima R.G, Araujo F.G, Maia M.F, de Silveira Braz Pinto A.S: Evaluation

of heavy metals in fish of the Sepetiba and Ilha Grande bays, Rio de Janeiro, Brazil. Environ. Res. 2002, A 89, 171-179.

FAO/WHO. Evaluation of Certain Food Additives and Contaminants: Technical Report Series 837; World health Organization: Geneva, Switzerland, 1993

Licata P, Trombetta D, Cristiani M, Giofrè F, Martino $D$, Calò M, Naccari F: Levels of toxic and essential metals in samples of bovine milk from various dairy farms in Calabria Italy. Environ. Res. 2004, 30, 1-6.

Llobet J.M, Falco G, Casas C, Teixido A, Domingo J.L: Concentrations of Arsenic, Cadmium, Mercury and Lead in common foods and estimated daily Intake by children, adolescents, adult and seniors of Catalonia, Spain. J. Agric. Food Chem., 2003, 51,838-842.

SEMA. Managment and environmental reclamation plan of baia from BamH to Sapetiba, Vol I, Secretaria de Estado de Meio Ambiente do Rio de Janeiro, 1998, Rio de Janeiro.

Toso B, Procid G, Stefanon B: 2002. Determination of volatile compounds in cows' milk using headspace GC-MS. J. Dairy Res. 69, 569577.

Reprints may be obtained from: Anastasio Aniello. E-mail anastasi@unina.it Tel.00390812536054 Fax 0039081458683 
Acta vet. scand. vol. 47 no. 1, 2006 